\title{
They passed with flying colours, but why are they failing now?
}

\begin{abstract}
To continue their studies to the pre university level, students need to excel in their Malaysian Certificate of Education Examinations. Pre-university education is provided by the Ministry of Education in the form of matriculation programs.. However a small number of these students who succeeded in enrolling into these matriculation programmes are not faring well. They either fail or are given conditional passes. The main purpose of this paper is to discuss findings of a research which aimed to investigate why these students are failing. A qualitative design employing in depth interview involving five respondents was undertaken. The findings reveal five important factors namely students' life style, attitude, adjustment to a different environment, the overloaded curriculum and lack of attention given by lecturers are contributory factors. The findings suggest that continuous monitoring of students' academic and social behavior need to be undertaken by the Matriculation centers. This means that early intervention in the form of tutorials, individual attention and counseling are crucial steps to be undertaken in order to prevent able students from dropping out.
\end{abstract}

Keyword: Matriculation, Underachieving 